\title{
O IMPREVISTO NO ESPAÇO DA EDUCAÇÃO INFANTIL
}

\section{Sueli Helena de Camargo Palmen}

RESUMO: Este artigo é resultado de uma pesquisa realizada em creche de universidade pública estadual. Aborda as relações criança-criança, criança-adulto, permeadas pelo espaçofísico, verificando qual a influência da organização espacial na prática educativa. Coloca para discussão e reflexão a importância das trocas de saberes entre os diversos sujeitos que fazem parte da creche, a importância do planejamento educacional e a importância da organização espacial, lembrando que estes elementos podem favorecer ou não o surgimento dos momentos de imprevisto na educação infantil, enquanto a participação da criança no planejamento.

PALAVRAS-CHAVE: Creche; Espaço-físico; Planejamento; Imprevisto; Cultura infantil; Cuidado; Educação.

\begin{abstract}
This article is result of a research realized in day-care center of public state university. Emphasis the child-child relationship and child-adult relationship permeated by physical space checking what the influence of the spacial organization in the educative practice. Put to discussion and reflection the importance of the chance of knowledge between different citizen that compose the day-care center, the importance of the planning educational and the importance of the spacial organization remind that this components can collaborate or can't collaborate the emerging of unpredictable moment in the early childhood education.
\end{abstract}

KEY-WORDS: Day-care center; Physical space; Planning education; Unpredictable; Childhood culture; Childcare; Education.. 
Este artigo traz parte da minha pesquisa (para o Trabalho de Conclusão de curso ${ }^{1}$ ) realizada no $\mathrm{CECI}^{2}$ - Centro de Convivência Infantil, que compõe o quadro de Programas Educativos ${ }^{3}$ existentes dentro da Universidade Estadual de Campinas, campus de Barão Geraldo/ Campinas.

Trata-se de uma creche no local de trabalho e em universidade pública e que traz em si a especificidade de ter sido criada visando atender aos direitos de suas funcionárias à educação e cuidado para seus filhos durante o período em que trabalham no interior dessa universidade. $\mathrm{O}$ seu funcionamento se dá em período integral, voltando-se a educação e cuidado de crianças que se encontram na faixa etária que varia de 3 meses à 4 anos de idade, tendo capacidade de atender até 300 crianças.

Por voltar-se a essa clientela restrita, torna-se homogênea e heterogênea ao mesmo tempo; homogênea, pois todas as crianças que tem sua vaga nesta creche possuem mães que estão no mercado de trabalho, como funcionárias desta universidade e heterogênea quando comparada as creches de bairro, pois tem a possibilidade de atender as filhas e

\footnotetext{
${ }^{1}$ Pesquisa realizada na área da Educação Infantil, durante o ano 2000, sob a orientação da profa. Dra. Ana Lúcia Goulart de Faria.

2 CECI - Centro de Convivência Infantil é integrante da pesquisa para a dissertação de mestrado de Fagundes (1997), referente a criação da creche da UNICAMP e faz parte de um programa do Governo do Estado de São Paulo iniciado em 1982, denominado Programa Centro de Convivência Infantil (CCI).

${ }^{3}$ Os demais programas educativos da UNICAMP são: CAS - Creche da área da saúde; PRODECAD - Programa de Desenvolvimento da Criança e do Adolescente; EMEI - Convênio UNICAMP/ Prefeitura; Escola Estadual de Ensino Fundamental Sérgio Porto e Centro Estadual Educação Supletiva.
}

filhos de mães de diferentes profissões, seja ela cientista ou servidora da ÚNICAMP, tornando possível uma rica troca cultural ${ }^{4}$. Como coloca Nogueira ${ }^{5}$ (1997) é no convívio das diferenças entre sexos, etnias, origens culturais e níveis sócio-econômicos que as trocas infantis ocorrem e é através delas que a criança tem a oportunidade "de construir a sua cultura” (p. 62).

Quanto a sua estrutura funcional, cabe lembrar que durante sua implantação, o CECI foi composto por profissionais da área da saúde, como enfermeiras e atendentes de enfermagem provindas do Hospital das Clínicas da UNICAMP. Tal dado demonstra qual ênfase foi atribuída ao cuidar e qual foi atribuída ao educar nesta instituição de educação infantil, em sua fase inicial.

Ainda hoje compõem o quadro de funcionárias do CECI profissionais da área da saúde como: psicólogas, nutricionista, enfermeiras e auxiliares de enfermagem, sendo a atual diretora dessa instituição uma enfermeira.

As recreacionistas que trabalham no CECI são mulheres com uma formação profissional diversificada, conforme levantou Finco $^{6}$ (2000) através do

\footnotetext{
${ }^{4}$ Fúlvia Rosemberg fez essa colocação sobre a especificidade das creches em universidades públicas, durante o $1^{\circ}$ Seminário de creches em universidades paulistas, que aconteceu em 15 de setembro de 2000, na UNICAMP, envolvendo profissionais das creches da USP, UNESP e UNICAMP.

${ }^{5}$ Nogueira pesquisou um programa de educação infantil para crianças de 4 a 6 anos situado na UNICAMP visando realizar a partir desta investigação o seu trabalho de conclusão de curso (Pedagogia/ UNICAMP).

${ }^{6}$ Finco realizou sua pesquisa sobre as concepções do brincar existentes entre as recreacionistas da mesma creche a que me reportei para o estudo dos
} 
mapeamento dessas profissionais. Engloba desde recreacionistas com formação do antigo primário até recreacionistas com formação em curso superior incompleto. Não há exigência quanto a uma formação profissional direcionada a área educacional.

Além das recreacionistas, atualmente, tal quadro também é composto por pedagogas, no entanto subordinadas à diretoria desta instituição.

Desde sua criação, o CECI da UNICAMP apresentou em si uma natureza de caráter assistencialista, um benefício do empregador e não como um direito da criança. (Fagundes, op. cit.; Finco, op. cit.)

Tal postura acaba por contradizer a legislação brasileira quanto à Educação Infantil, que por sua vez ressalta que:

- A creche e a pré-escola constituem simultaneamente um direito da criança à educação e um direito da família de compartilhar a educação de seus filhos em equipamentos sociais.

- A creche, assim como a pré-escola, é equipamento educacional e não apenas de assistência. Nesse sentido, uma das características da nova concepção de educação infantil reside na integração das funções de cuidar e educar. (MEC/ SEF/ DEP/ COEDI, 1998, vol. I: 10)

No CECI, entre os critérios seletivos para se atender a criança em seu interior, $o$ vínculo empregatício da mãe ${ }^{7}$ com a

momentos de imprevisto na educação infantil, o CECI.

${ }^{7}$ Destaco a figura materna, pois a implantação do CECI que ocorreu durante a gestão do Reitor Prof. Dr. J. A. Pinotti, estava ligada a implantação da amamentação compulsória, atendendo uma das determinações da legislação trabalhista, que era as
UNICAMP é o que determina a vaga na creche, desde que associada a uma avaliação da renda familiar que comprove a necessidade deste serviço. Vemos então o quão atrelada ao direito materno está associada esta imagem da creche.

Quanto a sua estruturação física, o CECI encontra-se dividido em dois prédios, distantes entre si. São eles:

- O prédio do berçário, que recebe crianças com a idade entre 3 meses à 2 anos, próximo ao prédio da FEA Faculdade de Engenharia de Alimentos; e

- O prédio do maternal, que recebe crianças com a idade entre 2 à 4 anos, próximo do $\mathrm{HC}$ - Hospital das Clínicas.

Essa pesquisa abrangeu os dois prédios, pois enfocou as práticas educativas, a organização espacial, as interações criança - criança e as interações criança adulto presentes tanto no berçário quanto no maternal.

Enquanto aluna do curso de Pedagogia da Faculdade de Educação da UNICAMP, desde o primeiro ano de meu curso observava, ainda que esporadicamente, de maneira informal e apenas externamente, o CECI - Centro de Convivência Infantil desta universidade.

Somente no $4^{\circ}$ ano do curso de Pedagogia, período em que o currículo do curso prevê a realização de estágio em Instituição de Educação Infantil é que tive a oportunidade de fazer uma visita ao CECI-maternal e assim conhecê-lo um

\footnotetext{
salas de amamentação no local de trabalho (Fagundes, op. cit.). Assim, estar realizando a amamentação natural quando se fosse pleitear uma vaga para seu filho ou filha, também já funcionou como critério de acesso ao CECI, em outros tempos.
} 
pouco mais aprofundadamente tanto externa quanto internamente.

Através deste contato é que percebi que seu espaço físico externo havia passado por reformas. Agora apresentava telas separando os parques das crianças pequenas daquelas um pouco maiores, ou seja, os ambientes externos são "parcialmente" abertos, pois apresentam tais limites de território.

A partir dessa observação passei a questionar o porquê de tal modificação em sua estrutura física e a questionar também como estariam acontecendo, no CECI, as situações educativas e o relacionamento entre suas crianças.

Quanto a essa questão, destaco aqui que as crianças são capazes de múltiplas relações (Musatti, 1998), como apresentam as teorias e pesquisas italianas, lembrando ainda a pesquisa das brasileiras Carvalho \& Beraldo (1989) na qual concluíram que as crianças preferem ao se relacionar com o outro, interagir com seus coetâneos à interagir com adultos.

Ressalto também que "a Pedagogia faz-se no espaço e o espaço, por sua vez consolida a Pedagogia" ( Faria, 1999a: 70), sendo assim interessante investigar a relação existente entre a organização espacial e as práticas educativas desencadeados no interior desta instituição de educação infantil, analisando o quanto oportunizam a expressão infantil.

Optei por estar observando as crianças na área da Educação Infantil, em creche $^{8}$, por se tratarem de crianças

\footnotetext{
8 De acordo com a Constituição Brasileira de
} 1988, a creche é uma instituição de educação pequenininhas, ... "faixa etária pouco pesquisada dentro do campo da Pedagogia”... (Bufalo, 1997, p. 5). Logo decidi por observar mais de perto as turmas do Berçário-4 (B-4) e do Maternal-1 (M-1), pois me permitiriam ver as práticas educativas existentes nos dois prédios do CECI, berçário e maternal, cada qual com sua organização espacial e localização diferenciada.

\section{A PROGRAMAÇÃo EDUCACIONAL DA CRECHE}

Em primeiro lugar, coloco que a programação educacional é uma responsabilidade da instituição educacional e ganha sentido quando possibilita a troca de conteúdos com os educadores, com os pais e demais interessados, fornecedores de "matéria prima" para a sua elaboração na creche, como ressalta Foni ${ }^{9}$ (1998: 158).

Durante o período em que estive no CECI, pude observar que a sua programação educacional é elaborada pela sua equipe técnica, composta por 04 pedagogas (dos módulos), 02 psicólogas, 01 nutricionista, 01 assistente social e 02 enfermeiras dessa instituição, contando ainda com a orientação de sua diretora (também enfermeira).

Com base nessa estruturação física é que acontece a discussão sobre quais as atividades que se realizarão, como será a organização dos espaços para tais

infantil para crianças com a idade entre 0 e 3 anos, na qual o binômio educar/ cuidar deve aí estar indissociado.

${ }^{9}$ Foni assim como Mussati, Cipollone, Mantovani e Verba, fazem parte das pesquisadoras italianas hoje traduzidas em português que dirigiram meu olhar neste trabalho, subsidiando e fundamentando essa pesquisa. 
atividades e qual será a participação dos pais dentro desta programação.

Contudo, pude observar que as recreacionistas que trabalham diretamente com as crianças - uma das principais protagonistas da vida na creche - ficam de fora dessa elaboração. Estas apresentam suas opiniões, anseios ou mesmo indagações sobre como organizariam um determinado momento na creche, para a pedagoga responsável pela orientação de seu respectivo módulo, cabendo a esta última transmitir às demais integrantes da equipe técnica tais sugestões.

Atitudes como essa ilustram como ocorre no CECI a separação entre quem pensa e quem faz, deixando de lado a elaboração conjunta, que por sinal não deve envolver somente equipe técnica e recreacionistas, mas envolver também as crianças e sua família, além dos demais funcionários da creche, cada qual dando sua contribuição, refletindo sobre o seu trabalho, criando saberes e principalmente compartilhandoos com o seu coletivo .

Cabe lembrar que ao abrir suas portas para a criança e sua família, a creche recebe a "cultura, o hábito, a história delas" ( Rossetti-Ferreira, Vitoria e Goulardins, 2000: 48) e tais elementos devem estar contemplados na programação educacional, tendo em vista uma relação de alteridade entre a diversidade e as múltiplas identidades que se encontram em seu interior.

Por ser uma creche de universidade pública na qual os seus usuários são de diferentes bairros de Campinas e região, o CECI comporta crianças com os mais variados costumes e com as mais diversas experiências culturais, tornando-se um rico ambiente multicultural. No entanto, ao elaborarem a programação educacional seguindo um modelo hierárquico (da direção e equipe técnica para as recreacionistas e para os usuários da creche: criança e família) essas diversidades se tornam invisíveis.

Refletindo sobre a forma como estão organizados os serviços nas instituições de educação infantil, coloco aqui que no CECI - Berçário, onde antes não havia apoio pedagógico, à partir de fevereiro deste ano incorporou-se à equipe técnica, uma pedagoga dentro de seu quadro funcional.

De certa forma, tal medida revela que o conceito de berçário vem se modificando no CECI. Pouco à pouco passa a ser visto como um local onde o binômio educação e cuidado das crianças pequenas buscam sua indissociabilidade, não restringindose dessa forma a somente a proporcionálas cuidados.

Com o apoio pedagógico desta nova profissional, as recreacionistas do berçário passaram a formar um grupo de estudo, no qual periodicamente ${ }^{10}$ discutem em conjunto algum assunto relacionado à educação infantil, à luz de textos selecionados pela pedagoga, tendo em vista atender suas necessidades de formação.

Cabe dizer que é dever das escolas reservar uma carga horária específica para a discussão, elaboração e reflexão sobre os elementos que compõem a sua dinâmica diária e por que também não das instituições de educação infantil?

\footnotetext{
${ }^{10}$ Porém sem contar com um agendamento das atividades a serem estudadas e discutidas, realizam-nas durante o horário de sono das crianças, por exemplo, aproveitando as brechas que surgem nesta creche, em função da formação em serviço.
} 
Esses momentos específicos podem estar voltados: tanto para a elaboração quanto para a reflexão sobre a programação educacional, como também para reunião com os pais e para a atualização permanente de seus educadores, como prevê a $\mathrm{LDB}^{11}$.

Contemplar tais momentos indica a busca pela "garantia da racionalidade $e$ da cientificidade do trabalho desenvolvido" (Cipollone, 1998: 121), valorizando a reflexão do grupo, a realização de pesquisa e a busca de soluções para os problemas que integram a vida na creche, propondo um aperfeiçoamento profissional em serviço.

Focalizando a constituição da Programação Educacional, destaco que a mesma envolve alguns componentes fundamentais para o entendimento de sua estrutura. Entre tais componentes estão: a organização dos grupos, a organização dos espaços e a organização do dia-a-dia.

A organização dos grupos está estritamente ligada com a proposta educacional da Instituição. No CECI é visível a organização rígida dos grupos. Cada um de seus módulos é específico às crianças que se encontram dentro de uma determinada faixa etária. Cabe lembrar que as crianças do berçário e do maternal não têm nenhum contato, principalmente por estarem inseridos em prédios diferentes.

\footnotetext{
${ }^{11} \mathrm{Na}$ Lei de Diretrizes e Bases para a Educação LDB 9.394/ 96, apresenta no art. 67 que - Os sistemas de ensino promoverão a valorização dos profissionais da educação, assegurando-lhes, inclusive nos termos dos estatutos e dos planos de carreira do magistério público; complementado através do seu inciso II - aperfeiçoamento profissional continuado; e em seu inciso V período reservado a estudos, planejamento e avaliação, incluído na carga de trabalho.
}

Destaco aqui o CECI-maternal, onde pude ver que a segmentação existente na organização dos grupos não se restringe apenas ao interior da creche. Em sua parte externa, o maternal apresenta cercas que delimitam os espaços e estes limites acabam por determinar com quem as crianças se relacionarão, dando a idéia de que existe perigo ao misturarmos as crianças pequenas com as maiores.

Cabe lembrar que esta segmentação por faixa etária remete ao modelo escolar, impedindo as trocas de experiências entre as crianças de diferentes idades, relação esta que é de grande importância no interior da creche, pois é através das trocas de experiências que as crianças recriam e criam cultura, como concluiu Nogueira (op. cit.: 1997).

Conforme afirmam Mantovani e Perani (1999) sobre essa forma de organização dos grupos na creche,

De partida, há sempre uma divisão um tanto rígida por faixas etárias, que encontra uma explicação na eficiência, na organização; a divisão em turmas na escola talvez tenha orientado essa opção. Em particular, o isolamento dos lactentes nos setores a eles destinados encontra a sua justificativa em bases higiênicosanitárias; este é porém um modo artificial (para o adulto e para a criança) de fazer crescer os pequenos. (p.82 grifos meus)

Segundo a publicação do MEC (1998) "Subsídios para credenciamento e funcionamento de instituições de Educação Infantil", os parâmetros para a organização dos grupos decorrerem da especificidade da proposta pedagógica de cada instituição. 
Paralelamente a organização dos grupos, articula-se à organização dos espaços e neste caso, ressalto que no CECI a organização espacial tanto do berçário 4 quanto do maternal 1, apresenta-se estruturada em módulos.

Esses módulos apresentam salas pequenas, sendo cada uma de um grupo específico de crianças e recreacionista, usadas basicamente para os momentos de sono e de conversas rápidas.

Não é o tamanho que determina a utilidade dessas salas, mas sim a forma como elas são utilizadas. Assim, poderiam funcionar como salas de múltiplos usos, onde a identidade de suas crianças pudessem lhe dar vida, contudo, possuem paredes vazias que não dizem nada à respeito das crianças que nela se encontram, apenas em seus momentos de sono (presentes na programação da creche).

Tanto o módulo do B-4 quanto o módulo do M-1 (além dos demais módulos do CECI) são de fácil limpeza, arejados e com poucos materiais ao alcance das crianças, sendo estes acessíveis quando oferecidos pelos adultos.

Isso ocorre devido a uma forte preocupação no interior dessa creche, com a saúde infantil e por isso é que procuram estruturar o seu espaço físico tendo como referencial medidas preventivas à poeira, às infecções e à qualquer situação que possa representar uma ameaça à criança.

A preocupação com a limpeza e a orientação em mantê-la como base (vindas da direção da creche), esbarra-se com os interesses educativos, como de expor na parede do módulo as produções infantis.
Nesses momentos de conflito entre o cuidar e o educar é que as recreacionistas criam estratégias visando dar espaço para o educativo na creche. Entre tais estratégias está a utilização de proteções de plástico para expor as produções infantis nas paredes do módulo, ou mesmo expô-las por um período curto de tempo, buscando evitar dessa forma a não valorização das produções das crianças e também o acúmulo de poeira. Tais momentos de conflitos e busca de solução para os mesmos revelam, ainda que discretamente, a busca pela indissociabilidade entre o educar e o cuidar.

Reporto-me a Foni (op.cit.), que após pesquisar a organização dos espaços de creches, enfatiza a importância dessa modalidade de organização, destacando que o espaço é também um conteúdo educacional.

Conscientizar-se sobre a importância da organização espacial é uma atitude necessária e que está em construção, apesar de ainda hoje ... "a grande maioria das creches apresentar uma estrutura arquitetônica parecida com a dos sanatórios, que assegura, quase que exclusivamente, ar, luz, espaços vazios e facilmente laváveis". (idem: 142)

Em relação a organização do cotidiano no CECI, a jornada diária das turmas B-4 e M-1, apresentam uma seqüência programática das suas atividades. O que pude perceber é que essa sequiência restringe a ação espontânea das crianças, pois quando as mesmas começam a se envolver em uma determinada atividade, numa determinada brincadeira, já é hora de dar seguimento a uma nova tarefa.

Isso indica que a programação diária deve ser repensada, buscando não interromper 
as relações estabelecidas entre as crianças numa dada circunstância, ou seja, não sendo um obstáculo segmentador, que controla suas ações, suas criações e suas interações.

As "quebras" ocasionadas por essa forma de organização da jornada diária podem ser flexibilizadas desde que se repense o que é prioridade dentro da creche: dormir mais ou brincar mais?

Formas de organização da jornada diária rígidas é que dificultam o surgimento das situações imprevistas dentro da creche, sendo estas fonte para a criação de cultura infantil, decorrentes das relações estabelecidas pelas crianças.

Pensar a programação, analisar cada atividade em profundidade, buscando ver sua importância tanto para a criança quanto para as recreacionistas e reavaliar a disposição dos tempos e espaços no diaa-dia na creche, sem restringir as ações das crianças, são hábitos que podem construir uma nova programação para o CECI rumo à uma Pedagogia da Educação Infantil.

Nesse ponto, conscientizar-se da importância das práticas educativas não castradoras é uma das medidas que possibilita melhorar gradativamente a qualidade da Educação Infantil.

\section{ENGLOBAR O IMPREVISTO ... QUAL A IMPORTÂNCIA?}

O rumo que a programação educacional tomará no interior da instituição de educação infantil associa-se à sua intencionalidade educacional.

Tomando como ponto de partida o CECIberçário, eu tinha como hipótese inicial que sua programação limitava-se a estipular tempos e espaços somente para os cuidados infantis.

Realmente o cuidar tem grande ênfase junto as crianças pequenininhas, mas não deveria limitar-se a isso.

Contudo, a introdução de uma pedagoga no quadro funcional desta creche, como mencionado anteriormente, pode ser um indicativo de que, pouco-a-pouco, a criança do berçário também terá seu direito à educação, ao cuidado e à brincadeira.

Durante o decorrer das atividades, a pedagoga e as recreacionistas procuram vincular o educar e o cuidar, lembrando que estas duas funções exercidas pela creche deveriam sempre ser consideradas como indissociáveis (Barreto, 1994).

No entanto, estas profissionais da educação infantil nem sempre conseguem realizar essa vinculação, pois recebem orientações da direção do CECI nas quais se sobressaem prescrições dirigidas ao cuidar e com forte influência higienista.

É através de mensagens diretas e indiretas de seu ambiente, como avisos de: "exclusivo para diarréia", "ambiente fechado é propício a infecção", ou informes do próprio espaço como ausência de tapetes (para evitar poeira), tinta a óleo nas paredes (favorecendo a limpeza), ausência de armários a altura da criança (com brinquedos a sua escolha), que começamos a perceber a maior importância atribuída ao cuidar, dissociada do educar nesta creche.

Dentro desse contexto, a pedagoga e as recreacionistas do berçário inserem mudanças gradativas nesse espaço, sem contudo passarem por cima das orientações voltadas à limpeza; por 
exemplo, organizando os brinquedos pelo salão do módulo no B-4, ou na parte externa dessa creche (Caderno de CampoBerçário, 01/08/2000), possibilitando que as crianças brinquem espontaneamente, dando-lhes maior abertura para se relacionarem com os demais colegas e juntos resolverem seus conflitos.

Ao contemplarem momentos em que a criança tem "uma certa liberdade", ainda que não com uma intencionalidade clara, planejada por parte das profissionais desta creche, dá-se a abertura para que imprevistos possam acontecer no berçário.

Propiciar o surgimento de situações inesperadas e imprevistas no interior da creche é permitir que as crianças se relacionem, inventem, se expressem e participem de sua educação.

Para consolidação de uma nova concepção de creche, que contemple o educar e cuidar como indissociáveis, vejo como necessária a elaboração de uma programação flexível e que seja fruto de um planejamento coletivo que dê espaço a espontaneidade infantil e às criações e interações das crianças, diferente do que acontece no CECI, onde as próprias recreacionistas são excluídas dessa elaboração.

Campos (1994) apresentando as idéias do italiano Catarsi, nos lembra que a programação "resulta de uma construção coletiva da qual a criança também faz parte: os educadores responsáveis pelo seu aspecto propositivo e as crianças

\footnotetext{
${ }^{12}$ Coloco dessa forma, "uma certa liberdade", pois apesar de permitir que as crianças gozem de momentos espontâneos, o adulto muitas vezes interfere em suas ações, limitando-as, às vezes por excesso de cuidados (ele tem medo que as crianças sozinhas briguem e se mordam, se machuquem, ...).
}

introduzindo os elementos casuais e não planejados" (p.333), pois também são seres sociais que estão em constante relação com o OUTRO, e juntos criam e recriam cultura sempre nos desafiando, como complementa Gusmão ${ }^{13}$ (2000).

Da mesma forma que educar e cuidar ocupam espaços de mesma importância na programação educacional, os elementos previstos e imprevistos também ocupam o seu.

Bufalo (1999a) aborda em seu vídeo "Creche: lugar de criança, lugar de infância” e em seu artigo "O imprevisto previsto " (1999b), o fato dos momentos de imprevistos não serem estudados na educação infantil. Também nos alerta sobre a importância dos momentos de expressão da criança: de sua criatividade, de sua iniciativa, de sua forma de ver e pensar o mundo. Contudo também ressalta a importância da observação por parte dos educadores e da importância de sua criatividade na prática educativa, atitudes básicas para a prática diária na Educação Infantil.

Por meio da observação o adulto também se torna um aprendiz, passa a conhecer melhor a criança, buscando-se alfabetizar nas suas cem linguagens infantis (Malaguzzi, apud Faria: 1999a), o que lhe permite responder ou ao menos tentar responder às "suas necessidades e ao inesperado" (Bufalo: 1999b: 121), lembrando que a creche também é um local de educação do adulto.

Considero que ao englobar os momentos inesperados criados pelas crianças na

\footnotetext{
${ }^{13}$ Agradeço a Profa. Neusa M. M. Gusmão, segunda leitora deste trabalho, pela leitura e comentários críticos que muito contribuiram para o enriquecimento desta pesquisa.
} 
programação, lhes damos voz e nos posicionamos como dispostos a ouvi-las, demonstrando através dessa medida o lugar que elas ocupam dentro da creche, o de protagonistas.

Quanto ao CECI-maternal, vejo que os momentos de imprevisto surgem devido a ação transgressora das crianças. As mesmas quebram ou procuram quebrar as regras impostas pelos adultos que funcionam como controles que limitam sua interação e as quais elas não vêem sentido.

Entre tais limitações temos como exemplo os momentos de espera pelo café da manhã no M-1, onde as crianças ficam sentadas em suas cadeiras, em grupos de 4 ou 5 crianças por mesinha, aguardando o momento do lanche.

É costume as recreacionistas oferecemlhes pecinhas de montar ou então animais de plástico e em miniaturas para que brinquem enquanto esperam, contudo, algumas crianças logo se cansam e começam a resmungar, a escorregar na cadeira e finalmente saem de seus lugares. Andam pela sala, correm em frente ao espelho e vão até as outras mesas "conversar" com os colegas.

Entretanto, essas formas de reação são interrompidas por alguma recreacionista, que leva a criança à sua cadeira novamente, visando através da repetição a assimilação da regra, indicando disciplina.

Mesmo sentadas as crianças inventam moda, criam brincadeiras que as tiram da monotonia. Brincam de bater as mãos na mesa, fazendo música, mexem ao mesmo tempo com a cabeça e fazem barulho com a boca. No entanto, logo o silêncio é requisitado pelas recreacionistas e pela pedagoga do M-1, pois parecem ver a hora da alimentação apenas como hora de saciar uma necessidade básica, deixando de lado as demais dimensões do ser humano: o lúdico, o afetivo, o artístico, o imaginário, etc.

Analisando as situações apresentadas no M-1, vemos as recreacionistas como reguladoras, disciplinadoras e transmissoras de regras que são cansativas e rígidas até mesmo para um adulto, quanto mais para uma criança que está disposta a brincar, movendo-se pelo espaço e mostrando que está viva.

Faria (1999a) ressalta a importância dos momentos de expressão da criança e da importância das instituições de educação infantil como espaço para se viver a infância, enfatizando que "as instituições de educação infantil deverão ser espaços que garantam o imprevisto (e não a improvisação) e que possibilitarão o convívio das mais variadas diferenças, apontando para a arbitrariedade das regras ...”( p.70)

Comparando as ações das recreacionistas e pedagogas do B-4 e do M-1, as diferenças aparecem.

No B-4 as profissionais procuram brechas para expressar o educacional sem menosprezar o cuidar, criando ainda que de forma não planejada, possibilidades para a expressão infantil.

Já no M-1 o educar parece ser visto como enquadramento às regras postas pelos adultos. No entanto, vejo que insistir para que a criança aprenda a esperar, fazendoa ficar sentada é forçar um aprendizado em detrimento de outros, possíveis através das múltiplas relações entre as crianças, através de brincadeiras por 
exemplo, onde também acontecem as trocas experiências.

É certo que o binômio "atenção/ controle" se faz presente nas instituições educacionais para a pequena infância tendo em vista educar as crianças a viverem em sociedade, mas

Cabe garantir que a balança penda para a "atenção" e o "controle" deverá estar voltado, não para o individualismo, o conformismo e a submissão, mas para o verdadeiro aprendizado da vida em sociedade: solidariedade, generosidade, cooperação, amizade. (Faria, 1999a: 72)

Possibilitar momentos de trocas entre as crianças de diferentes idades de diferentes grupos, em momentos diversos no decorrer do cotidiano, em espaços tanto internos quanto externos da creche, propicia que esses aprendizados aconteçam, além de tornar possível o surgimento do imprevisto, podendo o adulto utilizar-se dessas situações para conhecer melhor as especificidades infantis.

Enquanto no B-4 o imprevisto é garantido pelas profissionais (mesmo que sem essa intenção), no M-1 o imprevisto acontece através da transgressão infantil: são as crianças que criam condições para o inesperado e que burlam (até onde conseguem) as normas pré-estabelecidas nesta instituição. Estas diferentes atitudes sugerem que quanto maior a criança, mais necessário se torna o seu enquadramento no mundo regrado.

Finalizando esta questão, ressalto aqui a importância da oportunidade de expressão na creche: possibilitar ao profissional da educação infantil observador conhecer a criança com quem trabalha, alfabetizando-se em suas linguagens e possibilitar à criança manifestar-se e criar os momentos imprevistos, revelando o criar infantil e impondo-se como atorprotagonista no processo educativo da creche.

Veremos agora um pouco mais sobre um dos elementos que conforme sua organização, influência positiva ou negativamente as ações das crianças e das recreacionistas nas instituições de educação infantil: o espaço físico.

\section{A ORGANIZAÇÃO DO ESPAÇO FÍSICO}

"O espaço físico isolado do ambiente só existe na cabeça dos adultos para medilo, para vende-lo, para guardá-lo. Para a criança existe o espaço alegria, o espaço medo, o espaço proteção, o espaço mistério, o espaço descoberta, enfim, os espaços de liberdade ou de opressão" (Lima, 1989 apud Faria, 1999a: 70)

Como aponta o documento do Conselho Nacional dos Direitos da Mulher, "Creche urgente" (1988), a compreensão do espaço físico não pode ser vista de maneira isolada à proposta educacional da instituição de educação infantil. Dessa forma, pensar as creches e pré-escolas constituí-se numa responsabilidade, pois requer que pensemos seus espaços de acordo com as necessidades das crianças e adultos que nelas convivem.

O CECI apresenta hoje seu espaço físico repleto de cercas (principalmente no prédio do maternal) que delimitam os seus espaços. Também possuem salas específicas onde ficam colchões individuais para cada criança, propícios para os momentos de sono, mas que ao mesmo tempo limitam o lúdico ao não serem utilizadas como um espaço para o brincar e não apresentarem armários com 
brinquedos na altura das crianças, importantes para que estas possam fazer suas escolhas, demonstrar seus interesses, soltar sua imaginação.

Siebert (1998) ao estudar os espaços da educação infantil, concluiu que os adultos criam, muitas vezes, restrições às atividades infantis, ao dispor os objetos, os móveis, os enfeites, sob a sua perspectiva, deixando em segundo plano a perspectiva das crianças.

Diante de uma organização espacial adultocêntrica $^{14}$, a criança não explora o ambiente de maneira espontânea e quando tenta romper com essas barreiras muitas vezes tem sua iniciativa castrada pela intervenção do adulto que planejou determinado espaço.

A limitação das ações da criança, de seu contato com as pessoas, com os objetos, com os espaços em si 'torna-se um muro de vidro que engaiola a exploração infantil a qual, por intima natureza, está ligada ao movimento e às mudanças de lugar do corpo, ao pegar e ao lançar" (Siebert, op. cit.: 83).

Assim, os espaços pesquisados, tanto do berçário quanto do maternal possibilitam questionar quais os elementos e a forma de organização espacial que esta instituição vem priorizando e a qual é sua proposta educacional.

Nesse ponto, cabe lembrar aquilo que Dayrell (apud Faria, 1999a), enfatiza em relação às diversas formas para

\footnotetext{
${ }^{14}$ Rosemberg (1976) comenta criticamente que de acordo com essa concepção (adultocêntrica) a criança é enxergada como um ser apenas à espera do crescimento, um vir a ser adulto. Logo essa pesquisadora questiona essa visão e apresenta outra: a criança com suas especificidades, criadora de cultura e, portanto, um ser histórico.
}

estruturarmos o espaço, considerando-o enquanto um espaço ideológico:

"A arquitetura e a ocupação do espaço físico não são neutras. Desde a forma de construção até a localização dos espaços, tudo é delimitado formalmente, segundo princípios racionais, que expressam uma expectativa de comportamento de seus usuários (...) O espaço arquitetônico da escola expressa uma determinada concepção educativa” (p. 84).

Com base na estruturação interna do CECI, organizada por módulos, tanto berçário quanto maternal possuem salas parecidas em alguns aspectos e diferentes em outros.

As semelhanças encontram-se na existência de salas (as destinadas ao dormir e aos momentos de alimentação) iluminadas, com pintura e chão que facilitam a limpeza.

No entanto as diferenças entre o berçário e o maternal estão na forma como ambos utilizam esses espaços: no berçário - sala de dormir é para dormir, assim como no maternal, mas o salão utilizado para alimentação, no berçário supera essa função e permite que as crianças circulem pelos seus espaços, conhecendo-os, explorando os objetos que lhes estão disponíveis num dado momento, portanto ainda limitando de certa maneira a possibilidade de múltiplos usos desse espaço, já que essa forma de utilização (múltipla) é ocasional.

Já no maternal esse local é repleto de mesinhas e cadeiras, onde as crianças devem ficar durante os períodos de espera pela alimentação e durante a alimentação em si. 
As áreas internas e externas desta instituição têm seus espaços condicionados aos tempos presentes na programação da jornada diária, forçando uma divisão entre as atividades voltadas ao cuidar das destinadas ao educar, não demonstrando, pela forma como organizam os tempos e os espaços, a simultaneidade dessas duas funções, como deveriam ser desempenhadas nas instituições de educação infantil.

Quanto aos seus espaços externos, estes são vistos como áreas propícias ao brincar livre, apesar dos espaços não serem totalmente livres mas sim marcados por demarcações de espaços destinados a grupos específicos.

No berçário a área externa é constituída por uma vasta área verde, gramada, onde localizam-se brinquedos fixos que formam um parque, contudo também apresenta áreas cimentadas, onde as crianças passam grande parte do tempo, quando estão fora do módulo, brincando.

Em relação ao maternal os parques que rodeiam seu prédio são cheios de brinquedos, apresentando em alguns trechos solo gramado e em outros solo coberto por areia, folhas das árvores, enfim alterações feitas pela natureza. Contudo, essas partes externas e diferenciadas do maternal são segmentadas pelas telas de alambrados, reestruturando os grupos de crianças e recreacionistas nesse espaço, que ao contrário devia possibilitar as múltiplas relações e a espontaneidade infantil neste centro de educação infantil, sem restrições.

Assim vemos através dos dados até agora apresentados que berçário e maternal apresentam suas especificidades em relação aos espaços. Foram pensados e planejados, imbutindo em si concepções próprias de crianças, de saúde e de espaço coletivo.

A meta deve estar em procurar "superar os modelos rígidos de escola, de casa e de hospital" (Faria, 1999a: 70), afinal as crianças que vão para creche devem ter seus direitos respeitados, entre esses, à múltiplas experiências em ambientes pensado para elas, satisfazendo suas curiosidades, acolhendo-lhes e ao mesmo tempo desafiando-lhes, pois "todos sabemos que as condições ambientais favorecem ou desestimulam nossas atividades e nossos interesses" (Lima, 1994: 11).

Com base na bibliografia estudada sobre o tema em questão, vemos que o ambiente $^{15}$ da creche deve ser acolhedor, fazendo com que as pessoas que nele convivem parte de seu dia se sintam como seus componentes, no sentido de se verem reconhecidos em tais espaços.

Contudo, como pesquisou Gandini (1999), o ambiente também educa crianças e adultos e nesse sentido deve ser considerado um "terceiro educador" (p.157), indo além do acolhimento, como é comum no ambiente familiar, representado pela nossa casa.

Sob essa perspectiva, o espaço da creche "deve ser uma espécie de aquário que espelhe as idéias, os valores, as atitudes e a cultura das pessoas que nele vivem" (Malaguzzi,1984, apud Gandini, op. cit:157) favorecendo as múltiplas trocas de experiências entre os diferentes

\footnotetext{
${ }^{15}$ Forneiro (1998) coloca que o ambiente refere-se ao espaço físico, englobando também as relações que nele se estabelecem : afetos, conflitos, relações criança-criança, criança-adulto, crechesociedade-multiculturas.
} 


\section{ARTIGO EM TCC}

sujeitos, procurando garantir uma educação com base na alteridade.

Assim como é necessário superar os estereótipos trazidos de casa, é necessário superar os estereótipos hospitalares postos nas instituições de educação infantil.

Assim, as instituições de educação infantil devem ser espaços provocadores e que permitam a interação, compreendendo que é brincando que as crianças aprendem, estando os cuidados contemplados nesses momentos através de um planejamento adequado às especificidades infantis.

Convém ressaltar que propor espaços para que ocorra a "intersecção" (Forneiro, op. cit.: 244) dos diferentes grupos existentes na creche é tão importante quanto oferecer um lugar organizado para que a criança possa ficar sozinha, pensando em seus conflitos, tendo seus momentos de privacidade.

Os adultos também requerem tais cuidados. Necessitam assim como as crianças de espaços adequados as suas especificidades e que lhes possibilite momentos de descanso, necessários para evitar o desgaste provocado por um dia de trabalho (Faria, op. cit.).

Enfim, vemos a existência de uma relação entre a organização espacial com as práticas educacionais desencadeadas nas instituições de educação infantil, incitando à reflexão sobre a importância do espaço-ambiente flexível e versátil, contemplando a coletividade e "incorporando ambientes de vida em contexto educativo” (Faria, 1999a: 78).

Episódio : Quem está dentro quer sair. E quem está fora quer entrar?
"O ser humano cresce num ambiente social e a interação com as pessoas é fundamental".

\section{Vigotsky}

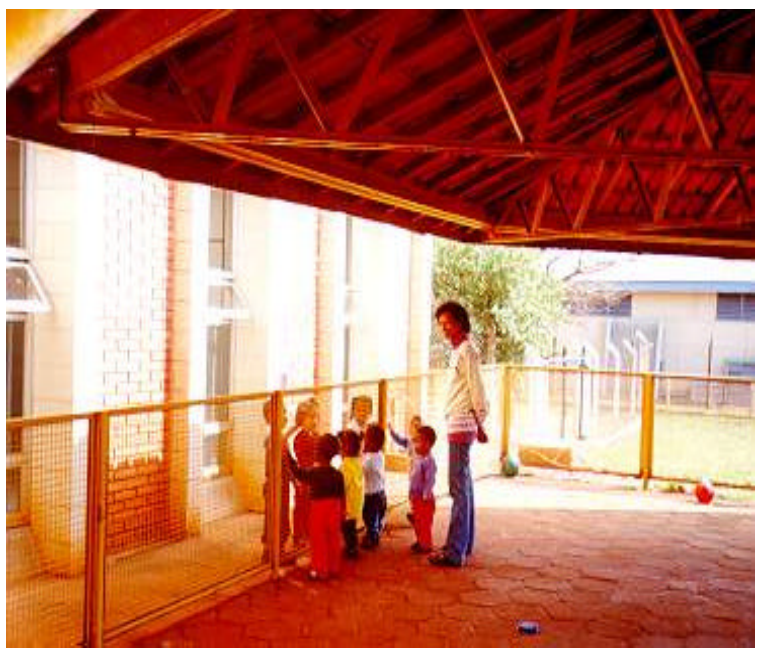

Figura 1 - Professora e crianças do Maternal I

As crianças do Maternal $1-B$, que são as crianças pequenininhas quando comparadas com as demais crianças dessa creche (CECI -Maternal), são levadas até o quiosque cercado tendo em vista separá-las das demais turmas dos maternais. A pedagoga do módulo oferece bolas às crianças, para que elas possam brincar nesse espaço. Essa pedagoga fica junto deste grupo de crianças, enquanto as duas recreacionistas trocam as fraldas de outras crianças dessa turma, no banheiro do módulo, próximo ao referido quiosque. Depois de "limpas", as crianças retornam ao cercado até que dê o horário do almoço.

A pedagoga canta algumas músicas infantis (Atirei o pau no gato; Fui na feira comprar limão; Casinha enfeitada de cupim, ...) $e$ conversa com as crianças do M-1. Passado algum tempo algumas crianças (maiores) se aproximam do cercado e se agarram as suas grades, demonstrando tentativa de contato. A pedagoga observa essa tentativa de interação entre as crianças maiores com as pequenas, mas não interfere. 
Do cercado, as crianças do M-1 são levadas ao seu módulo, cuja entrada fica próxima ao quiosque. É a hora do almoço.

(Caderno de Campo: 17/08/00; Maternal 1)

Enquanto pesquisadora questiono por que não há liberdade para que ocorra a interação entre as crianças pequenas com as maiores, como revelou essa tentativa frustrada descrita no episódio acima. Qual a função das cercas além de barrar essa tentativa de contato entre as diferentes idades?

A instituição de Educação Infantil apresenta-se como um espaço favorecedor do encontro entre as diferenças de idade, de gênero, de raça, de credo e de origem social dos indivíduos que nela passam parte de seu dia.

Enquadrando-se nessa condição, cabe dizer que o CECI conta com um espaçofísico privilegiado, pois possui amplas áreas verdes e arborizadas, onde ocorrem o brincar espontâneo da criança, como já constatou Finco (op. cit.).

Diante dessa estrutura privilegiada, compreender o porquê da presença de cercas espalhadas pela parte externa do CECI, especificamente no prédio do Maternal, se torna uma tarefa complexa.

Com base nas observações feitas no período em que estive nesta creche e apoiando-me nas falas presentes em seu interior, a hipótese que me leva a entender a importância atribuída às grades que formam as vastas áreas cercadas do prédio do Maternal é a da superproteção para com as suas crianças.

A esse respeito Faria (1999a) enfatiza que:
$O$ espaço externo e interno, deve permitir o fortalecimento $d a$ independência das crianças: mesmo sendo seguro, não precisa ser ultraprotetor, isto é, em nome da segurança não deve impedir experiências que favorecem o autoconhecimento dos perigos $e$ obstáculos que o ambiente proporciona. (p. 79)

Organizar os espaços da creche, tendo em mente a segurança com as pessoas (pequenas e grandes) que nela convivem, compõe uma das preocupações constantes no documento oficial criado em 1995 "Critérios para o atendimento em creches que respeite os Direitos Fundamentais das crianças" (Campos e Rosemberg, 1995). Tal documento complementa ainda que as crianças têm o direito de conviver num ambiente seguro, mas que não deixe de ser estimulante, desafiador e que lhes permita desde pequenos, o brincar ao ar livre junto à outras crianças e outros adultos, diferentes daqueles de seu universo familiar, e em diferentes espaços, possibilitando-lhes novas experiências.

Segundo Siebert (op. cit.):

"A idéia da segurança, levada ao extremo, sugere que gaiolas $e$ barras sejam lugares ideais para o crescimento, mas tratar-se-ia de um crescimento às custas do crescimento da pessoa no sentido da autonomia”. (p.83)

A preocupação com a segurança das crianças no CECI é expressa por suas cercas, contudo em demasia, acabando por delimitar as interações entre as crianças, segmentando-as em grupos etários, fazendo-nos lembrar do modelo escolar, que é seriado (cada idade em uma 
série), apesar desta creche não apresentar em seus princípios o caráter escolarizante.

Ao estimular e dar liberdade para as interações sociais, tornando possível o encontro entre os diversos parceiros (crianças e adultos) e consequentemente a troca de suas experiências, criamos brechas para que se instaure na creche uma Pedagogia das Interações. Esta tem como fundamento o favorecimento da autonomia e construção da identidade pela criança, num espaço de convivência agradável e que lhe propicia "as trocas de idéias", como aborda Machado (1999).

O momento de ida ao parque no CECI, no caso do maternal é quando acontece o encontro de uma turma de Maternal 1 com outras turmas, juntando ainda que não intencionalmente e de maneira não planejada as crianças de diferentes idades no mesmo espaço, acontecendo nesse instante brechas para a troca de experiências entre essas crianças. As mesmas utilizavam essas ocasiões para as suas criações, brincadeiras, vôos da imaginação em conjunto.

A compreensão do mundo, suas contradições e sua diferença se dá, portanto, através do contato com a diversidade cultural, social, étnica, entre outras diversidades. É através do DIÁLOGO $^{16}$ entre as crianças e os adultos na creche que ocorre $o$ compartilhar dessas diferenças, enfatizando o papel dessa instituição: cuidado e educação de crianças, " que ai vivem, convivem, exploram, conhecem, construindo uma visão de mundo e de si

\footnotetext{
${ }^{16}$ Esse diálogo, entretanto, nem sempre é verbal, mas se estabelece através do choro, do sorriso, do sacudir das grades, etc. Enfim, a comunicação também é corporal.
}

mesma, constituindo-se como sujeitos". (Oliveira, 1992: 64)

Como coloca Bufalo (op. cit.): $O$ processo das crianças conhecerem a si próprias e ao Outro é fundamental, pois o adulto e as crianças não são iguais e nem estabelecem entre eles relações de iguais, porque há diferenças que não se pode negar. Portanto, um desafio está posto: como educar e cuidar das crianças sem ter como objetivo aniquilar todas as diferenças, mas, convivendo com elas de maneira sadia, de maneira a serem complementares, mesmo que sejam contrárias, pois acredito que também no confronto muito se revela, se aprende e se conquista. (p. 29)

Mesmo sem essa intencionalidade educacional, momentos como esse surgem no CECI, e as crianças se aproveitam dessas ocasiões para $\underline{\mathrm{o} \text { fazer }}$ acontecer, para as suas invenções e suas interações junto aos seus colegas maiores e menores e junto de outros adultos, como as demais recreacionistas presentes nesta creche.

Se tais momentos de encontro ocorrem independente das restrições expressas pela organização espacial desta creche, por que as cercas permanecem demarcando territórios?

Favorecer a interação entre as crianças nos mais variados espaços, livrando-as dos obstáculos que restringem as trocas com seus coetâneos, constitue uma das funções das recreacionistas da creche e de todos aqueles que pensam essa instituição enquanto um local de cuidado e educação.

Retomando a foto inicial, desencadeadora dessa discussão, vemos a busca de contato entre as crianças de dentro do 
quiosque cercado e as crianças que se encontram fora desse espaço.

Observando atentamente, podemos ver que são crianças de diferentes idades que deixam de lado os brinquedos do parque (as crianças de fora) ou as bolas espalhados pelo chão do quiosque (as crianças de dentro), demonstrando através dessa atitude maior interesse em se comunicarem com seus colegas.

Essa cena vem de encontro com a pesquisa das brasileiras Carvalho e Beraldo (1989) que concluí que as crianças preferem interagir com outras crianças à interagir com os adultos, estabelecendo relações prolongadas e significativas com seus coetâneos.

Verba e Isambert (1998) também comprovaram através de pesquisas sobre as trocas entre as crianças que a mistura de idades pode ser enriquecedora para o grupo, desde que as situações de trocas não sejam limitantes "para permitir que as crianças expressem a própria criatividade e as suas próprias capacidades de exploração e que tenham relações harmoniosas" (p.258).

Retomando Dutoit (1999): "para a criança é muito enriquecedor não ficar confinada o tempo todo num mesmo espaço, com a mesma organização e com as mesmas pessoas" (p. 43).

Assim, finalizo esse episódio questionando qual a função das cercas senão impedir as crianças de se relacionarem entre si, permitindo que juntas criem novas brincadeiras, sentimentos, que troquem experiências e assim construam a cultura infantil.

O controle através de cercas não estará impedindo o surgimento de situações imprevistas, que revelam a fantasia infantil, a criatividade da criança e a sua capacidade criadora, enfim, construtura de cultura?

Este é mais um ponto que fica para reflexão.

\section{CONSIDERAÇÕES FINAIS}

Questionamentos sobre a importância da organização espacial nas instituições de educação infantil, procurando ver quais os objetivos existentes nesses espaços e suas relações com os momentos de imprevisto criados pelas crianças, conforme sua estruturação, é que definiram a temática deste trabalho.

A creche, cenário dessa pesquisa tem uma característica específica: está dividido em dois prédios - o do berçário e o do maternal, localizados em locais diferentes e distantes entre si dentro da universidade. Ambos apresentam especificidades não só em termos de faixa etária a que se destinam, mas também em termos de organização dos tempos/espaços e de estrutura de funcionamento.

Em relação ao berçário, a recente inserção de uma pedagoga no seu quadro funcional indica uma fase de transição desta creche: o educar está sendo visto como uma necessidade mesmo no berçário, onde fica a direção desta instituição (enfermeira), mesmo que ainda prevaleça nesse local orientações de ordem higienista.

Assim, mesmo contando com o apoio de uma pedagoga, se sobressai nesta creche a importância do cuidar. Portanto, o educar e o cuidar não são trabalhados de forma indissociável enquanto direito da criança. 
No maternal isso não é diferente. Isso ocorre devido a existência de uma jornada diária rígida com grande preocupação com os momentos de sono, de alimentação, para com os controles de peso e altura e de higiene no interior do CECI.

É assim no espaço externo de ambos os prédios do CECI (berçário e maternal) que as crianças têm uma maior liberdade para a expressão das suas cem linguagens.

Mesmo diante de barreiras estruturais como delimitações espaciais por cercas de alambrados (maternal) ou atenções superprotetoras (berçário e maternal) as crianças reagem em busca de expressão e interação com seus coetâneos: transgridem regras e encontram brechas para o seu contato com o espaço físico organizado e natural e para o contato com seus colegas de outras turmas e de outras idades, cada qual com sua diversidade.

Lembro aqui que é através da organização espacial que a gama de relações que permeiam a vida na instituição de educação infantil vão se constituindo.

Cabe ao educador ter consciência da importância de se atentar para a forma como organiza os espaços, os materiais, ..., pois como nos lembra Cipollone (op. cit.) é o educador o responsável pela organização dos espaços de maneira que as crianças possam ser indiretamente orientadas ao uso do ambiente, permitindo-lhes fazer escolhas de acordo com suas necessidades. Assim, tal organização deve ser bem pensada, pois os materiais disponíveis e sua disposição podem condicionar a ação das crianças, muitas vezes até limitando aquilo que elas podem fazer.
O espaço interno do berçário e do maternal são espaços anônimos no sentido de não expressarem a diversidade de suas crianças. As salas dos módulos do B-4 e do M-1, assim como as demais salas dos outros módulos do CECI, não expressam em suas paredes a diversidade que ali convive.

Ao se encontrarem, principalmente nos espaços esternos do CECI - berçário e maternal, as crianças têm a chance de estabelecerem relações com seus colegas e desencadearem nesses momentos atos não previstos na jornada diária.

Momentos imprevistos podem ser extremamente enriquecedores, pois trazem em si expressões do imaginário infantil, permitem múltiplas trocas de experiências entre as crianças, dá oportunidade à criança a aprender a conviver com as diferenças, ampliando assim seu repertório de conhecimentos, e fundamentalmente a meu ver, permitem aos adultos conhecerem a criança nas suas "cem linguagens", através de suas cem formas de se comunicar.

Dessa forma, o imprevisto não é importante unicamente à criança, enquanto um meio que lhe permite viver a infância, é também importante ao adulto, enquanto meio que lhe propicia descobrir e conhecer a criança: o adulto é também posto na condição de aprendiz.

Vejo como rica a heterogeneidade sociocultural presente no CECI, dessa forma considero que seus espaços deviam ser organizados visando ampliar as trocas entre as crianças para além das fronteiras postas pelos módulos, possibilitando a multiplicidade de relações.

Cada espaço da forma como se apresenta ocupado e organizado na creche transmite 
em si valores e concepções daquele que o organizou, influenciando nas práticas educativas.

Vemos atitudes contrastantes por parte das recreacionistas quando as observamos brincando no parque junto das crianças, mas controlando-as e vigiando-as quando estão no interior da creche.

Dessa forma é que os espaços ganham significados ocultos:

- ao ar livre o espaço do CECI, tanto do berçário quanto do maternal, é destinado ao brincar; e

- o interior da creche, espaço para o "trabalho sério", para o "pedagógico".

Compreenda-se aqui "trabalho sério" como trabalho didatizado, no qual o lúdico também é regrado. Deduz-se assim que o brincar livre não é visto como parte do trabalho pedagógico nesta creche, é mais um passa tempo dentro da instituição educacional.

Nesse ponto enfatizo aqui que a forma como os espaços estão organizados, assim como a forma que o trabalho na creche se estrutura e se realiza, refletem as concepções de quem nela trabalha, principalmente daqueles que participam da elaboração de sua programação educacional.

Assim sendo, a estruturação rígida dos tempos/ espaços no CECI são reflexos de sua estrutura hierárquica. Toda essa rigidez dentro dessa instituição condiciona as recreacionistas a desenvolverem certas atitudes perante a criança. São poucas que se mantém atentas no processo, permitindo brechas a ação infantil e lutando contra a alienação.

No entanto, diante de ações imprevistas criadas pelas crianças, que permitem a criação de cultura infantil e que são momentos de sua expressividade, retomo Faria (1999b) e concluo que "nossos professores nem sempre sabem brincar $e$ não estão preparados para trabalhar com $o$ inesperado, com o conhecimento espontâneo criado pela criança”. (p.22)

Isso ainda representa um desafio e requer uma tomada de consciência sobre a importância da formação do profissional de educação infantil e a necessidade de refletirmos sobre qual a função da creche, lembrando que estamos nos referindo a uma instituição educativa coletiva, diferente de casa, da escola e do hospital. Portanto, a questão vai para além da organização espacial da creche: é uma questão de concepção desse direito à educação, no qual a organização do espaço físico é apenas um aspecto.

É preciso que se crie uma reflexão sobre as crianças como o outro na creche que nos inquieta e nos surpreende, como um enigma, que nos desafia e desafia nosso conhecimento, como aponta Larrosa (apud Gusmão, 2000), enfim como um ser que não só imita, mas também se relaciona com o outro trocando informações, criando imprevistos, arte ... culturas.

\section{REFERÊNCIAS BIBLIOGRÁFICAS}

BARRETO, Angela M. R. Por que uma política de formação do Profissional da Educação Infantil? Por uma política de formação do profissional da Educação Infantil. Brasília: MEC, p. 11-15, 1994.

BUFALO, Joseane M. P. Creche: lugar de criança, lugar de infância. Um estudo sobre as práticas educativas em um CEMEI de Campinas/SP. Campinas, SP, 1997. Dissertação (Mestrado). Faculdade de Educação, UNICAMP. 
, Creche: lugar de criança, lugar de infância. Direção: Ondina Fonseca. Campinas, SP, 1999a. Fita de vídeo. FAEP - UNICAMP. 12 min. , color.

, O imprevisto previsto. Pro-

Posições, Campinas: Faculdade de Educação/ UNICAMP, vol. 10, n.1 (28), p. 119-131, mar. 1999b.

CNDM, CECF. Creche Urgente - O espaço físico. Brasília, vol. 3, 1988.

CAMPOS, Maria M. Educação Infantil no primeiro mundo: Uma visão daqui debaixo do Equador. In: ROSEMBERG, Fúlvia, CAMPOS, Maria M. (org.) Creches e Pré-escolas no Hemisfério Norte. São Paulo: Cortez: Fundação Carlos Chagas, 1994, 323-353.

\section{ROSEMBERG, Fúlvia.}

Critérios para um atendimento em creches que respeite os direitos fundamentais das crianças. Brasília, MEC/ SEF/ DEP / COEDI, 1995.

CARVALHO, Ana Maria A. , BERALDO, Katharina E. A. Interação criança-criança: ressurgimento de uma área de pesquisa e suas perspectivas. Caderno de Pesquisa, São Paulo, SP: Fundação Carlos Chagas, n. 71, p. 55-61, nov. 1989.

CIPOLLONE, Laura. A Atualização permanente nas creches. In: BONDIOLI, Anna, MANTOVANI, Susanna (Org.). Manual de Educação Infantil: de 0 a 3 anos - uma abordagem reflexiva. $9^{\text {a }}$ edição. Porto Alegre: Artes Médicas, 1998, p. 121-139.

DUTOIT, Rosana A. A interação de crianças de idades diferentes como conteúdo da Educação Infantil. Criança,
Brasília, DF: MEC, n. 32, p. 38-43, jun. 1999.

FAGUNDES, Magali dos Reis. A creche no trabalho ... $O$ trabalho na creche: um estudo do Centro de Convivência Infantil da UNICAMP - trajetórias e perspectivas. Campinas, SP, 1997. Dissertação (Mestrado). Faculdade de Educação, UNICAMP.

FARIA, Ana Lúcia G . O espaço físico como um dos elementos fundamentais para uma Pedagogia da Educação Infantil. In: FARIA, Ana Lúcia G., PALHARES, Marina S. (Org.). A Educação Infantil Pós - LDB: rumos e desafios. Campinas, S.P.: $\quad$ Autores Associados.-FE/ UNICAMP; São Carlos, SP: Editora UFSCar; Florianópolis, SC: Editora da UFSC, 1999a. p.67-97

Cultura: $\begin{gathered}\text { Educação Pré-Escolar e } \\ \text { para uma pedagogia da }\end{gathered}$ educação infantil. Campinas, SP: Editora da UNICAMP, São Paulo: Cortez, 1999b.

FINCO, Daniela . As concepções do brincar entre as recreacionista do CECI (Centro de Convivência Infantil da UNICAMP). Campinas, SP, 2000. Trabalho de Conclusão de Curso (Pedagogia). Faculdade de Educação, UNICAMP.

FONI, Augusta. A Programação. In: BONDIOLI, Anna, MANTOVANI, Susanna (Org.). Manual de Educação Infantil: de 0 a 3 anos - uma abordagem reflexiva. $9^{a}$ edição. Porto Alegre: Artes Médicas, 1998, p.140-160. 
FORNEIRO, Lina I. A organização dos espaços na Educação Infantil. In :

ZABALZA, Miguel A. Qualidade em Educação Infantil. Porto Alegre: Art Med, 1998, p. 229-281.

GANDINI, Lella. Espaço Educacionais e Envolvimento Pessoal. In: EDWARDS, Carolyn; GANDINI, Lella, FORMAN, George (Org.). As cem linguagens da criança: a abordagem de Reggio Emilia na educação da primeira infância. Porto Alegre: Editora Artes Médicas, 1999, p.145-158.

GUSMÃO, Neusa M. M. Desafio da diversidade na escola. Revista MEDIAÇÕES. Depto. de Ciências Sociais, Centro de Letras e Ciências Humanas, Universidade Estadual de Londrina - UEL, jun./ dez. 2000.

KISHIMOTO, Tizuko M. Política de formação profissional para a educação infantil: Pedagogia e Normal Superior. Educação \& Sociedade, Campinas: Cedes, Especial. N. 68, p. 61 - 79, dez. 1999.

LIMA, Mayumi W. S. A importância da qualidade do espaço na educação das crianças. Criança, Brasília, DF: MEC, n. 27, p. 9 - 12, 1994.

MACHADO, Maria L. A. Criança pequena, educação infantil e formação dos profissionais. Perspectiva, Florianópolis, SC, vol. 17, n. especial, p. 85-98, jul.-dez. 1999.

MANTOVANI, Susanna e PERANI, Rita Montoli. Uma profissão a ser inventada: O educador da primeira infância. ProPosições, Campinas: Faculdade de Educação/ UNICAMP, vol. 10, n.1 (28), p. 75 - 98, mar. 1999.
MEC/ SEF/ DEP / COEDI. Subsídios para credenciamento e funcionamento de instituições de Educação Infantil. Brasília, vol. I e II, mai. 1998.

MUSATTI, Tullia. Modalidades e problemas do processo de socialização entre crianças na creche. In: BONDIOLI, Anna, MANTOVANI, Susanna (org.). Manual de Educação Infantil: de 0 a 3 anos - uma abordagem reflexiva. $9^{\mathrm{a}}$ edição. Porto Alegre: Artes Médicas, 1998, p. 189-201.

NOGUEIRA, Denise Cristina. A criança pequena produz cultura? Um Estudo Introdutório sobre o Convívio das Diferenças entre Crianças Pré-Escolares. Campinas, SP, 1997. Trabalho de Conclusão de Curso (Pedagogia). Faculdade de Educação, UNICAMP.

OLIVEIRA, Zilma M.; MELLO, Ana M.; VITÓRIA, Telma; FERREIRA, Maria C. R. Creches: crianças, faz de conta \& cia. Petrópolis, RJ: Vozes, 1992.

PALMEN, Sueli H. C. O lugar do imprevisto no espaço da educação infantil. Campinas, SP, 2001. Trabalho de Conclusão de Curso (Pedagogia). Faculdade de Educação, UNICAMP.

ROSEMBERG, Fúlvia. Educação para quem? Ciência e cultura, v. $28, \mathrm{n}, 12$, p.1466-1471, 1976.

ROSSETTI-FERREIRA, Maria C., VITÓRIA, Telma, GOULARDINS, Liliane G. Quando a criança começa a freqüentar a creche ou pré-escola. In: ROSSETTI-FERREIRA, Maria C. (et. al., org.). Os Fazeres na Educação Infantil. $2^{\mathrm{a}}$ edição. São Paulo: Cortez, 2000. P.4751 . 
SIEBERT, Renate. O adulto frente à criança: ao mesmo tempo igual $\mathrm{e}$ diferente. In: BONDIOLI, Anna, MANTOVANI, Susanna (Org.). Manual de Educação Infantil: de 0 a 3 anos uma abordagem reflexiva. $9^{a}$ edição. Porto Alegre: Artes Médicas, 1998, p.77-87.
VERBA, Mina, ISAMBERT, Annalise. A construção dos conhecimentos através das trocas entre as crianças: estatuto e papel dos "mais velhos" no interior do grupo. In: BONDIOLI, Anna, MANTOVANI, Susanna (Org.). Manual de Educação Infantil: de 0 a 3 anos - uma abordagem reflexiva. $9^{\mathrm{a}}$ edição. Porto Alegre: Artes Médicas, 1998, p.245-258. 